\title{
Evaluation of cost efficiency in tomato greenhouses: the case of seven agrobussines in México, 2016
}

\section{Marisol Arvizu ARMENTA}

\section{Centro de Investigación en Alimentación y Desarrollo AC, México}

\begin{abstract}
:
Aim: The main objective of this research was to evaluate the efficiency of economic costs in seven units of greenhouse tomato production, during the production cycles of 2016, through the application of the stochastic frontier, depending on the type of packaging they handle and the cost structure that governs them.
\end{abstract}

Design / Research methods: The stochastic frontier model includes the analysis of the non-systematic random component, which assumes an extremely critical role in the analysis during the interpretations. With the calculation of the stochastic cost frontier we construct the cost inefficiency index represented by $\mathrm{C}_{-}$it, delimited below 0 . The index shows the percentage in which the cost is exceeded and, therefore, the degree of inefficiency.

Conclusions / findings: The elaboration of the stochastic frontier finds its justification in the argument that the less efficient competitor is the one that receives the greater effects of the competition. In this sense, the location of the companies analyzed with respect to their own line of efficiency is essential for the design of the strategies of each company. The production units analyzed showed that, on some occasions, externalities are the cause of inefficiency, but contrary to what is established in theory, there are some units that show that the inefficiency with which they count is diminished by The influence of uncontrolled variables.

Originality / value of the article: The contribution of this research lies in the use of efficiency models in the primary sector, specifically in tomato's greenhouses..

Key words: Stochastic Frontier Model, Efficiency in Costs, tomato's Greenhouses

JEL: D14, Q13

Correspondence address: Marisol Arvizu ARMENTA, Centro de Investigación en Alimentación y Desarrollo AC, Carretera a La Victoria KM 0.6 CP. 83304, Hermosillo, Sonora, Mexico. E-mail: marisol.a.armenta@gmail.com

Received: 21.12.2017, Revised: 11.02.2018, Revised: 30.05.2018, Revised: 30.06.2018, Accepted: 30.06.2018

doi: http://dx.doi.org/10.29015/cerem.576 


\section{Introduction}

The tomato (Lycopersicon esculentum mill), is one of the most commercialized vegetables in the world, with more than 177 million tons during 2016. In tomato production the top ten countries are: China (31.8\%), India (10.3\%), United States of America (7.3\%), Turkey (7.1\%), Egypt (4.4\%), Italy (3.6\%), Islamic Republic of Iran (3.5\%), Spain (2.6\%), Brazil (2.3\%) and Mexico (2.2\%) (FAO 2018).

The production of this vegetable configures a value chain that involves a series of links among which are: consumers, marketers, suppliers, governments and producers. In 2016, Mexico is positioned as the leading tomato exporter worldwide, the exported value of US $\$ 2.1$ billion it was equivalent $53.3 \%$ of the national production of this vegetable, and $99.3 \%$ of sales of Mexican tomatoes went to the United States (CIA 2017). Tomato production is highly concentrated, the $54.1 \%$ of the national total in 2015 was produces in five entities; Sinaloa (27.4\%), Michoacán (7.2\%), San Luis Potosí (7.2\%), Baja California (7.1\%) and Jalisco (5.2\%). (FIRA, 2016).

In tomato production, as in agricultural systems in general, the incorporation of technology has influenced in the increase of productivity and the efficiency of the value chain. Creating an intricate network of marketers-producers who have as their goal compliance with quality standards and just-in-time delivery processes such as those in automotive and aeronautical industries.

The technologies to tomato production can be classified into two broad areas: open field and protected agriculture. The first ones are involved traditional activities where production takes place outdoors at the mercy of insect's attack and climatic effects. The second form use protector infrastructures (greenhouses and shade screens) that cover the crop from inclement weather, pests and diseases.

Therefore, the technology in greenhouses allows stepped production in harvest times to complement traditional production, since these closed and transparent structures allow the construction of the ideal artificial microclimate to grow plants out of season in good conditions, allowing continuity in the production and good prices (Henao 2001). 


\section{EVALUATION OF COST EFFICIENCY IN TOMATO GREENHOUSES}

In México, the area sown in a conventional manner (open field) was reduced to an average annual rate of 6.7 percent between 2005 and 2015, going from 73,960 to 36,848 hectares. The decrease of the cultivated area in this cultivation modality has been greater in some entities such as Sinaloa, Baja California and Jalisco. On the other hand, the area established with protected agriculture (greenhouse and shade screens) increased from 395 to 13,747 hectares in the mentioned period, that is, it grew at an annual average rate of 42.6 percent. Greenhouse cultivations is concentrated in Sinaloa, Baja California and Jalisco, although it has also acquired greater importance in other entities such as Colima, State of Mexico, Hidalgo, Michoacán, Querétaro, San Luis Potosí, Sonora and Zacatecas. The increase in the surface area with protected agriculture infrastructure is attributed mainly to the success in the harvest of tomato quality export that is intended to the United States market (FIRA 2016). In this article, only the producers who wanted to share the necessary information for the study were consulted, the main tomato producing states were consulted in the greenhouse and the results of those who agreed to participate were presented.

Authors such as (Calvin, Cook 2005; Cook, Calvin 2005); analyze from the economic perspective tomato production in greenhouse, and have focused on marketing channels, production lines, cost structure and governance relationships between sellers, producers and buyers and they evaluated the generated employment and the economic multiplier effects generated.

Other studies such as (Engindeniz, Tuzel 2006), make an economic analysis of a greenhouse in Turkey, from its installation and its operation emphasizes the economic feasibility associated with the expansion of these greenhouses. On the other hand (Dodson 2002), studies the diversification of production from organic tomato production technologies (Mysore, Weng-Fei 1999), focuses on the economic dimensions of greenhouses in the United States, analyzing the multiplying effects of the production.

Somewhere research to evaluate the economic efficiency in tomato production show the main approaches to approach through which the issue of tomato economic efficiency has been investigated. From the perspective of profitability benefit-cost engaged in making comparisons using measures such as the ratios of physical 
productivity (divided product inputs) or average costs (cost divided product) (Sánchez López et al. 2004; Torres Lima et al. 2004; Rubocoa et al. 2016); use of Cobb Douglas functions (Ibitoye et al. 2015); estimation of shepherd-future coefficient and exponential model of combined profit function (Ayoola 2014), among others.

Since this is an economic activity that involves international competition, producers must conceive their investment project considering all the elements that demand efficiency in production and the search for profitability in a competitive environment where prices are the indicators that mark the fluctuations of supply and demand.

In this sense, there are aspects that are not considered in these analyzes of profit, such as: sector weaknesses, high capital costs, technical and management inexperience, as well as the shortage of suppliers of specialized inputs and/or services, infrastructure and technology, etc.

In the international field, following Laurinavičius (2017), there is a profuse literature that addresses the issue, only to cite some authors we list some of the research products Productive efficiency of agricultural sector is extensively analyzed (Gorton, Davidova 2004). A number of studies have been attempted to investigate the issues of efficiency by using widely applied frontier methods. Asmild nad Hougaard (2006) analyzed the influence of environmental improvement potential to efficiency of Danish pig farms. Davidova and Latruffe (2007) related the Czech farm efficiency to financial management. Vasiliev et al. (2008) employed the DEA method to analyze the efficiency of Estonian grain farms after Estonia's transition to the market economy and during the accession period to the European Union (EU). Rasmussen (2010) used SFA in the form of input distance functions to estimate efficiency of Danish crop, dairy and pig farms. Bojnec and Latruffe (2011) analyzed the relationships between size and efficiency of Slovenian farms.

However, there is an unfilled gap in the research on the analysis of the efficiency in production costs of Mexican protected agriculture from the perspective of stochastic frontier analysis of production and costs.

The present research aims to perform a stochastic frontier analysis in costs in tomato's greenhouses: seven agrobusiness in México, 2016. Using for this purpose 


\section{EVALUATION OF COST EFFICIENCY IN TOMATO GREENHOUSES}

the models originally proposed by Aigner et al. (1977) and Meeusen and Van Den Broeck (1977), and adapted by Stevenson (1980), and which includes the nonsystematic random component in substitution of those variables that are omitted and affect profitability.

This document is divided into 6 sections: The structure of costs in greenhouses; the stochastic frontier model; Characterization of companies and description of the variables; Packaging costs, variables not controlled, controlled and determinant; Monte Carlo simulation-application model; and conclusions.

\section{The structure of costs in greenhouses}

In the analysis of the economic dimensions and the profitability of the greenhouses, the cost structure and the evaluation of the efficiency of the same stand out. The economic cost is defined as:

"The economic cost analyzes the company thinking about the future, the allocation of scarce resources waiting to know what the cost will be in the future and how the company could reorganize its resources to reduce it and improve its profitability, therefore, the economic cost is equal to the cost of lost opportunities where there are costs that the company can and can't control" (Pindyck 2009: 208).

At International level cost efficiency has been analyzed with different models, some authors have applied the stochastic frontier model for agriculture, such as the Taiwanese case studied by Hung et al. (2008). This author applied the cost stochastic frontier model in a pure way to estimate the cost frontier and the efficiency of each company, to make the location of these in relation to the cost frontier.

Kvaløy and Tveteras (2008) studies the cost structure and vertical integration having as main contribution in the analysis of the curve of the average costs and the relation that they have as the scale of production.

Bateman et al. (2006) investigates the benefits and costs of agriculture in the framework of a strategy implemented by the European Union to give relation to the 
management and the cost of water in this primary activity, to analyze the structures of costs before and after the application of such strategy.

At the Latin American level Benach (2005) studies agricultural and industrial production cost models, analyzes the cost models used in rice production in Costa Rica, and designs proposals for new cost-of-production models. Reyes (1995) uses an econometric model of linear programming for different combinations of research and development, interest rates and agricultural prices, obtaining an efficient production structure and costs.

At the national and local level, the identified studies have focused on two aspects, the first one is that proposed by Kido (2007), who makes a comparative analysis of costs, analyzes the efficient cost and the opportunity cost having as two scenarios the planting of maize or the reforestation of the area in question. The second is that of Sánchez et al. (2004), who calculates the average cost of production of cotton to reach a point of equilibrium and characterizing the structure of costs and production of the company.

\section{The stochastic frontier model}

The stochastic frontier model includes the analysis of perturbations or nonsystematic random component that substitutes or represents those variables that are omitted or ignored and that affect the product but which a deterministic or statistical model was not included in the analysis.

Within this logic, the error term replaces all variables that are not included in the analysis model for which there are different meanings. The non-systematic random component assumes an extremely critical role in the analysis of the models of stochastic frontier function that is seen during the interpretations that can be given to the model and hence the importance of using the stochastic frontier function model.

This model, proposed by Aigner et al. (1977) and Meeusen and van den Broeck (1977) where stochastic efficiency is assumed to follow a normal distribution of means. More flexible assumptions with respect to efficiency distribution were developed in the literature when including the truncated normal distribution of 


\section{EVALUATION OF COST EFFICIENCY IN TOMATO GREENHOUSES}

Stevenson (1980) which allows a vector to be truncated positively so that the efficiency depends on specific variables.

The general model is:

$$
\begin{aligned}
& \ln C_{i t}=\ln C_{i t}^{D K}+v_{i t}+u_{i t}(1) \\
& \ln C_{i t}^{D K}=f\left(X_{i t}+Z_{i t} ; \beta, \delta\right) \\
& v_{i t} \sim N\left(0, \sigma_{v}^{2}\right), \quad(3) \\
& u_{i t} \sim N\left(u_{i t}, \sigma^{2}\right), u_{i t} \geq 0, \quad \text { (4) } \\
& u_{i t}=z_{i t} \gamma .
\end{aligned}
$$

Where:

$\ln \boldsymbol{C}_{i t}$ : is the logarithm for total costs.

$\ln C_{i t}^{D K}:$ The kernel is the determinant of the production frontier that is defined by the function (f). The kernel determinant is a function of two vectors of variables $\mathrm{X}_{\mathrm{it}} \mathrm{y} \mathrm{Z}_{\mathrm{it}}$, and their corresponding coefficients of vectors $\beta \mathrm{y} \delta$ which is based on a standardized logarithmic cost function, where $\mathrm{X}_{\mathrm{it}}$ contains the logarithms of the products as quantities $y_{i t}$ and prices as inputs and the terms of interaction between them.

$v_{i t}$ is a random variable of mean 0 and with normal distribution. The importance of this distribution is that it allows modeling numerous natural, social and psychological phenomena. While the mechanisms underlying much of this type of phenomena are unknown, because of the sheer number of uncontrollable variables involved in them, the use of the normal model can be justified by assuming that each observation is obtained as the sum of a few independent causes, the normal distribution is important because of its relationship with the estimation by ordinary least squares.

$\boldsymbol{u}_{i t}$ is the variable that captures the effect of cost inefficiency which is a measure of the additional cost as a percentage of the minimum cost. It is assumed that the random variable follows a normal distribution.

$\boldsymbol{Z}_{i t} \boldsymbol{Y}$ this part a positive coefficient indicates that the growth in an exogenous variable cause that the inefficiency in the cost increases (Battese, Coelli 1995). As 
indicated in equation (2) the vector $\boldsymbol{Z}_{i t}$ is included in the minimum cost function, which means that within of the exogenous variable in $\boldsymbol{Z}_{i t}$ not only changes the distance between the current cost of the minimum, but can even shift the cost frontier $\ln C_{i t}^{D K}$.

\section{Characterization of companies and description of the variables}

The method followed by this investigation requires the description of companies and the variables that will be used to measure the efficiency of the unit, in addition to explaining each of the steps that are necessary for the application of the stochastic frontier model of cost. The companies that participate in this evaluation are tomatoproducing units in greenhouses that have medium and high technology (Table 1).

The stochastic frontier of cost makes a count of the distance that has the current cost of the company and the frontier given by the established conditions and the variables used for the construction of this one, is due to this that for the interpretation of the indicators resulting from the model will be interpreted in a suitable way placing the production unit in the context of its productive indicators.

\section{Table 1. Productive indicators}

\begin{tabular}{|l|l|l|l|l|l|l|l|}
\hline $\begin{array}{c}\text { Indicators } \\
2016\end{array}$ & Monterrey & Saltillo & Parral & Cuauhtémoc & Sonora & Guanajuato & Sinaloa \\
\hline $\begin{array}{l}\text { Size of the } \\
\text { company } \\
\left(\mathrm{M}^{2} \text { total }\right)\end{array}$ & 45,240 & 50,000 & 40,000 & 20,000 & 50,400 & 50,000 & 200,000 \\
\hline $\begin{array}{l}\text { Unitary } \\
\text { Performance } \\
\left(\mathrm{Kg} / \mathrm{M}^{2}\right)\end{array}$ & 40.00 & 27.00 & 56.00 & 32.00 & 19.50 & 19.42 & 14.00 \\
\hline $\begin{array}{l}\text { Average } \\
\text { Selling } \\
\text { Price }(\$ / \mathrm{Kg})\end{array}$ & 16.20 & 16.30 & 9.20 & 8.29 & 15.00 & 14.00 & 15.00 \\
\hline Technology & High & High & High & Medium & Medium & Medium & Medium \\
\hline
\end{tabular}

Source: information provided by producers of 7 tomato producing greenhouses.

Notes: Kilograms (Kg); Square meters $\left(\mathrm{M}^{2}\right)$; Mexican pesos (\$). 


\section{EVALUATION OF COST EFFICIENCY IN TOMATO GREENHOUSES}

For the application of the model it is necessary to employ two types of variables, controlled and not controlled by each production unit. In the first instance, we have the uncontrolled variables, for this investigation we consider 3, the market price, the exchange rate and the price of natural gas in 2016. This type of variable shows the influence that the exterior has inside the structure of cost of the companies.

\section{Packaging costs, variables not controlled, controlled and determinant}

The controlled variables are represented by the cost structure of the producing units involved in the analysis. The companies analyzed do not necessarily have homogeneous accounting entries, making the controlled variables that are necessary for the application of the model incomparable. With this background, the first necessary step for the correct application of the model was the homologation of the cost structures remaining as shown in Table 2.

\section{Table 2. Structure of cost of production of greenhouse tomato}

\begin{tabular}{|c|}
\hline 1. Production Indicators \\
\hline $\begin{array}{l}\text { 1.1. Size of the Company }\left(\mathrm{M}^{2} \text { totales }\right), 1.2 \text { Unitary Perfomance }\left(\mathrm{Kg} / \mathrm{M}^{2}\right), 1.3 \text {. Average Selling Price } \\
(\$ / \mathrm{Kg}), 1.3 .1 \text {. Average exportation selling price }(\$ / \mathrm{Kg}), 1.3 .2 \text {. Average national sellin price }(\$ / \mathrm{Kg}) \text {, } \\
\text { 1.4. Technology }\end{array}$ \\
\hline 2. Income per Hectare \\
\hline 2.1. Main Product (Fresh Tomato), 2.2. Packaging maquila, 2.3. Government Payments \\
\hline 3. Operation costs by hectare \\
\hline $\begin{array}{l}\text { 3.1. Variability costs, 3.1.1. Seeds (Vegetative material), 3.1.2. Growing substrate (soil treatment), } \\
\text { 3.1.3. Fertilizers, 3.1.4. Packaging, 3.1.5. Electric Energy, 3.1.6. Gas } \mathrm{CO}_{2} \text {, Fuel, 3.1.7. Chem/Bio } \\
\text { Supplies, 3.1.8. Water, 3.1.9. Workforce, 3.1.10. Freight, 3.1.11. Comercialization, 3.2 Other } \\
\text { variable costs, 3.2 Fixed Costs, 3.2.1. Company Admin, 3.2.2. Depreciation of assets, 3.2.3. Other } \\
\text { fixed costs }\end{array}$ \\
\hline
\end{tabular}

Source: author's elaboration based on information of 7 greenhouses producers of tomato, homologation suggested by FIRA (2016).

Once the structure is homologated, the variables to be applied within the model should be calculated per square meter and per kilogram to calculate the economic indicators of the company (break-even point and operating profit of kilogram per square meter). 
The cost of production of Monterrey, which should be mentioned is a company that has a high technology, almost 700 pesos per square meter and the Sinaloa, medium technology, with less than 100 pesos, other companies have its cost in a range of less than 600 and more than 200 pesos depending on the level of technology in which they are. Then the percentage of the main costs are presented, these are fertilizer, $\mathrm{CO}_{2}$, labor, packaging and freight, with the highest cost being the packaging.

\section{Graphic 1. Comparison of greenhouse tomato production costs in 7 Mexican companies, for 2016}

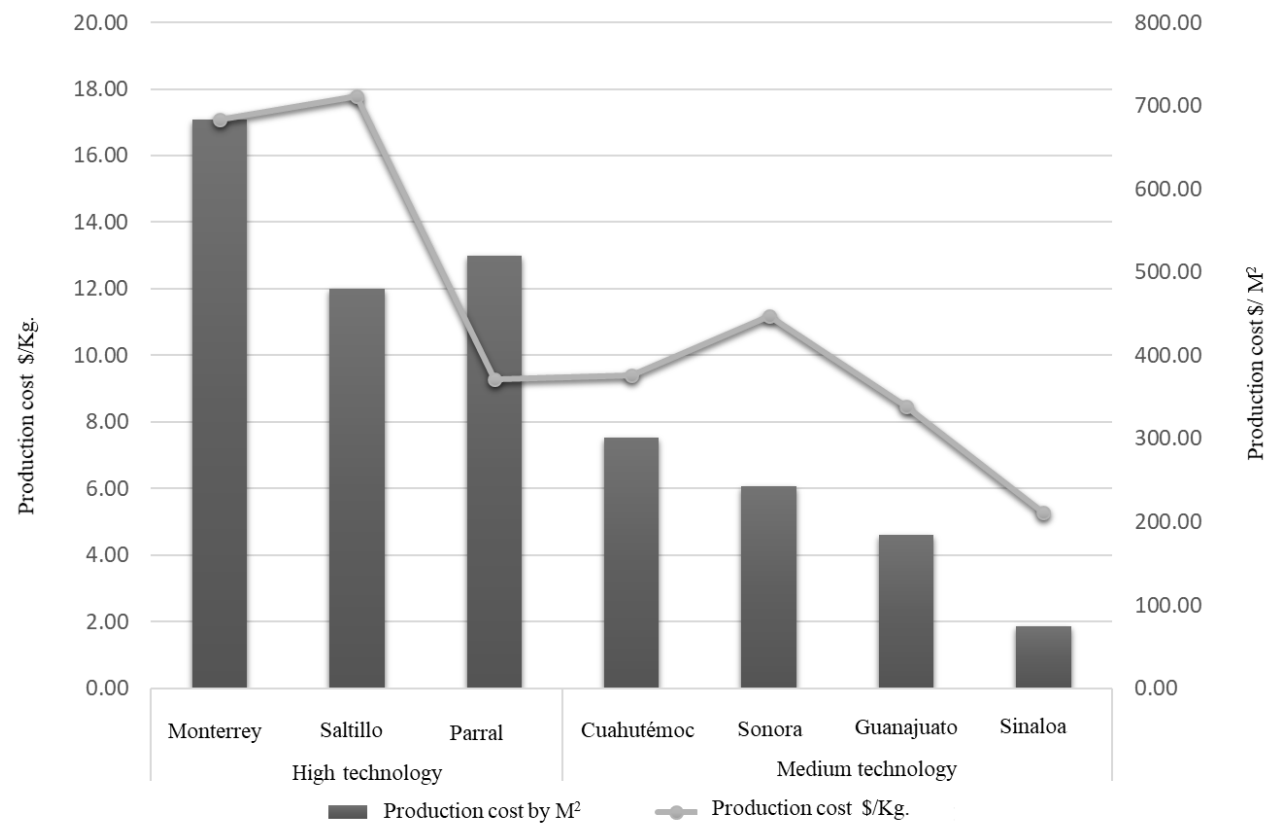

Source: author's elaboration based on information of 7 greenhouses that produce tomato.

As can be seen in the previous section, the packaging plays a dominant role over other accounting entries reported by all companies, representing in some companies up to $92 \%$ of total costs, becoming a determinant variable in the total cost of the company, see Table 3. 
Graphic 2. Composition of variable production costs of high tech greenhouse tomato on 2016

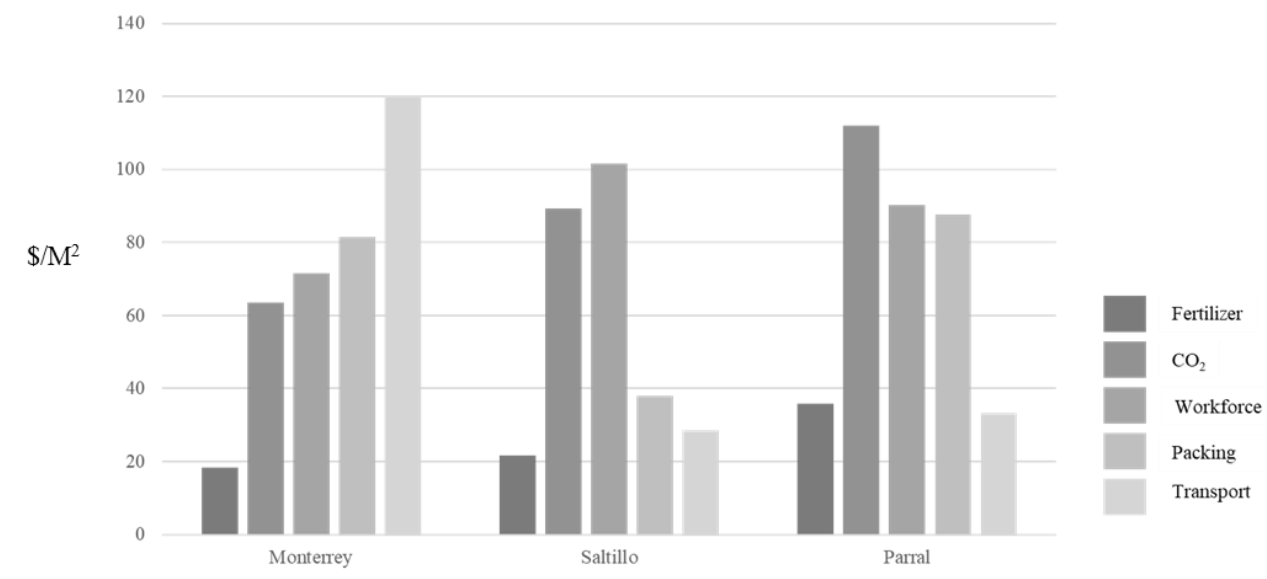

Source: author's elaboration based on information of 7 greenhouses that produce tomato.

Graphic 3. Composition of variable costs of production on greenhouses with medium tech that produce tomato

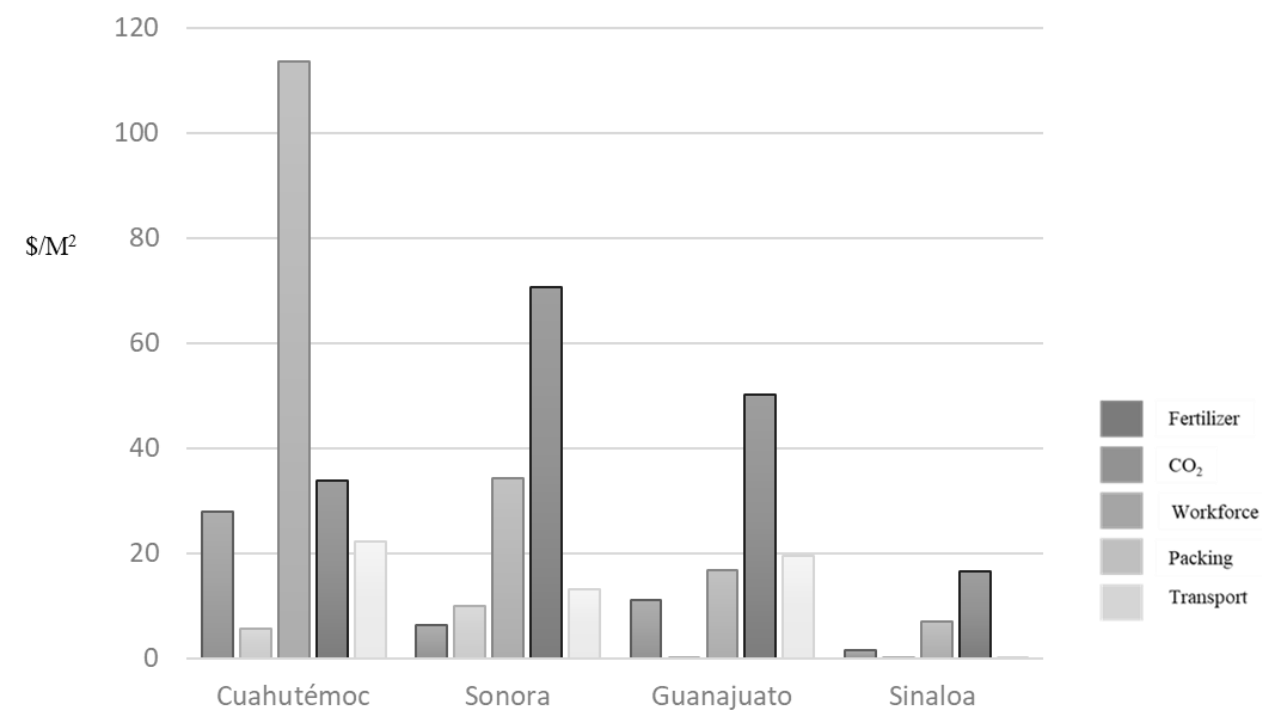

Source: author's elaboration based on information of 7 greenhouses that produce tomato. 
Table 1. Average of packing above total cost

\begin{tabular}{|l|l|l|l|}
\hline \multirow{2}{*}{$\begin{array}{l}\text { Technology } \\
\text { level }\end{array}$} & City/State & Packing & Non Packing \\
\cline { 3 - 4 } & & Average & Average \\
\hline \multirow{3}{*}{ High } & Monterrey & $88.08 \%$ & $11.92 \%$ \\
\cline { 2 - 4 } & Saltillo & $92.08 \%$ & $7.92 \%$ \\
\cline { 2 - 4 } & Parral & $83.15 \%$ & $16.85 \%$ \\
\hline \multirow{3}{*}{ Medium } & Cuauhtémoc & $88.73 \%$ & $11.27 \%$ \\
\cline { 2 - 4 } & Sonora & $70.80 \%$ & $29.20 \%$ \\
\cline { 2 - 4 } & Guanajuato & $72.81 \%$ & $27.19 \%$ \\
\cline { 2 - 4 } & Sinaloa & $77.59 \%$ & $22.41 \%$ \\
\hline
\end{tabular}

Source: author's elaboration based on information from 7 greenhouses that produce tomato.

\section{Table 4. Definition of variabilities}

\begin{tabular}{|l|l|l|l|}
\hline Fixed cost & $\begin{array}{l}\text { Market price by: } \\
\text { Type of packaging }\end{array}$ & Variability cost & $\begin{array}{l}\text { Packaging price by } \\
\mathrm{Kg}\end{array}$ \\
\hline & Type of change & Total cost & \\
\hline & Natural Gas price & Clearing Price & \\
\hline
\end{tabular}

Source: author's elaboration based on information of 7 greenhouses that produce tomato.

In Table 4 the variables defined for the application of the simulation are presented:

- Fixed cost: fixed costs reported by companies.

- Market price by type of packaging: these represent the daily costs per type of tomato packaging in two high and low price scenarios, the most used packages in the market are: $5 \mathrm{~kg}$ Carton, $5 \mathrm{~kg}$ Flats, 10lbs, 11lbs, $15 \mathrm{lbs}$ and 25 pounds; the simulated market price was the average monthly price per kilogram reported by USDA for the year 2016.

- Exchange rate: Daily peso-dollar exchange rate reported by Bank of Mexico for the year 2016.Natural gas price: quarterly natural gas price reported by Bank of Mexico for the year 2016.

- Total cost and variable cost: costs reported by companies.

- Packaging cost per kg: cost reported by the company. 


\section{Monte Carlo simulation and application of the model}

The variables to be simulated will be weighted on their participation in the total cost to obtain a closer approximation to reality with the Monte Carlo simulation performed. The simulation is done by Excel spreadsheet in which 1,000 tests are carried out with controlled simulations applied to the uncontrolled and controlled variables. The decision criterion for choosing the variables to be applied in the stochastic frontier model is the profitability of the variables.

The stochastic cost-regression regression yields the results as shown in Figure 1, applied in the STATA software 14. In the first instance, we have the regression where the dependent and independent variables interact, the model has the property of separating the statistical error of the stochastic error for which the variables differ.

The interpretation is based on two components of the regression, the first is the sign and the second the coefficient. The sign shows whether the inefficiency is presented positively or negatively. In the case of the coefficient reflected in which percentage is increased or decreased inefficiency.

Figure 1. Stochastic cost-regression regression yields

\begin{tabular}{|c|c|c|c|c|c|c|c|}
\hline & & & & ce) vh & (cxe) cost no & rate $(100)$ & \\
\hline Stoc. Fr & atier no & $\mathrm{mal} / \mathrm{half}-\mathrm{nor}$ & 1 model & & $\begin{array}{l}\text { Number of } \\
\text { obs }\end{array}$ & $=$ & 916 \\
\hline Log loke & ihood & $=$ & 4105.218 & & $\begin{array}{l}\text { Wald chi2 } \\
\text { (2) }\end{array}$ & $=$ & $7.79 \mathrm{E}+07$ \\
\hline & & & & & Prob > chi2 & $=$ & 0.0000 \\
\hline & & Coef. & Std. Err. & $\mathrm{z}$ & $\mathrm{P}>|\mathrm{z}|$ & {$[95 \%$ Conf } & [nterval] \\
\hline $\mathrm{ctm} 2$ & & & & & & & \\
\hline & price & -0.0001668 & 0.0001473 & -1.13 & 0.257 & -0.0004555 & 0.0001219 \\
\hline & cxe & 0.9724754 & 0.000114 & 8528.85 & 0.000 & 0.9722519 & 0.9726989 \\
\hline & _cons & 3.559906 & 0.0003809 & 9344.82 & 0.000 & 3.55916 & 3.560653 \\
\hline $\ln \operatorname{sig} 2 \mathrm{v}$ & & & & & & & \\
\hline & cxe & -7.911996 & 0.17225 & -45.93 & 0.000 & -8.2496 & -7.574392 \\
\hline & _cons & 2.764299 & 0.3099484 & 8.92 & 0.000 & 2.156811 & 3.371787 \\
\hline $\operatorname{lnsig} 2 \mathrm{u}$ & & & & & & & \\
\hline & price & 5.088877 & 0.6825449 & 7.46 & 0.000 & 3.751113 & 6.42664 \\
\hline & _cons & -19.22836 & 0.8975534 & -21.42 & 0.000 & -20.98753 & -17.46919 \\
\hline
\end{tabular}

Source: Author's own elaboration. 


\subsection{Cost stochastic frontier}

In the application of the model the distribution of stochastic error was obtained in two different scenarios with each one of the uncontrolled variables proposed and by the types of scenario that the database provides by making classification highly and inefficient.

\section{Random variable: market price by type of packaging and scenario}

In the case of the market price (Table 5), in the high price scenario the Cuauhtémoc company presents a high inefficiency because its coefficients reach $9.416 \%$, in the case of the 11-pound package which is the one that represents the greatest inefficiency for the company followed by the 15-pound package in which $6.017 \%$ inefficiency increases as well as the 5-kg Carton package, then there is the 25 -pound packaging that increases inefficiency by $2.788 \%$ for the company.

The packaging that increases to a lesser extent the inefficiency of Cuauhtémoc's company is 10 pounds, since its inefficiency would increase by $0.142 \%$, all given the conditions presented in the analyzed year, since this distribution is conditional on an average annual exchange rate of 2016, reported by the Bank of Mexico and an average annual price of natural gas of 6,99 .

Table 2. Distribution of stochastic error by the type of packaging of high price

\begin{tabular}{|c|c|c|c|c|c|c|c|}
\hline \multirow{2}{*}{\multicolumn{2}{|c|}{ States with inefficiency }} & \multicolumn{6}{|c|}{ price by type of packaging } \\
\hline & & \multirow{2}{*}{$\begin{array}{l}5 \quad \mathrm{Kg} \\
\text { Carton } \\
6.008\end{array}$} & \multirow{2}{*}{$\begin{array}{ll}5 \quad \mathrm{Kg} \\
\text { Flats } \\
\\
\\
1.394\end{array}$} & \multirow{2}{*}{$\begin{array}{l}\frac{10}{\text { Libras }} \\
0.142\end{array}$} & \multirow{2}{*}{$\begin{array}{l}\begin{array}{l}11 \\
\text { Libras } \\
9.416\end{array} \\
\end{array}$} & \multirow{2}{*}{\begin{tabular}{|l|}
$\begin{array}{l}15 \\
\text { Libras }\end{array}$ \\
6.017 \\
\end{tabular}} & \multirow{2}{*}{\begin{tabular}{|l|}
$\begin{array}{l}25 \\
\text { Libras }\end{array}$ \\
2.78
\end{tabular}} \\
\hline & Cuauhtémoc & & & & & & \\
\hline & Sonora & 1.304 & 4.713 & 0.083 & 13.654 & 5.899 & n.a. \\
\hline \multirow{3}{*}{ Little Inefficient } & Guanajuato & -0.023 & -0.261 & 0.056 & -0.352 & -0.041 & 0.587 \\
\hline & Saltillo & 0.023 & -0.104 & -0.506 & -0.036 & -0.430 & 4.820 \\
\hline & Sinaloa & -0.195 & 0.162 & 0.000 & -0.359 & 0.142 & 0.274 \\
\hline
\end{tabular}

Source: author's elaboration based on information provided by producers.

The company located in Sonora, within the scenario of high prices, presents significant levels of inefficiency, especially in the 11-pound package as it increases by $13.654 \%$, without forgetting that in all types of packaging analyzed has an 


\section{EVALUATION OF COST EFFICIENCY IN TOMATO GREENHOUSES}

increase of inefficiency ranging from $5.899 \%$ to $0.083 \%$. In contrast to observing the behavior of stochastic error that has the company of Sinaloa can be noted that the levels of inefficiency it handles are minimal and fluctuate between $0.274 \%$ and $0.359 \%$.

For the low price scenario (Table 6), with the aforementioned conditions of the exchange rate and the price of natural gas, there is a distribution of the error completely different from that obtained in the scenario of the high price, since for four types of packaging was not found convergence, which means that the cost structure is adequate for this scenario, with these types of packaging being $5 \mathrm{~kg}$ Flats, 11,15 and 25 pounds, while for the Carton $5 \mathrm{~kg}$ package and 10 pounds the inefficiency increases considerably in $15 \%$ and $2 \%$ respectively.

As for the situation shown by the Sinaloa company, its cost structure is not affected to an important extent by changes in the random variable; shows small coefficients of increase in inefficiency, as shown by the 25-pound pack which is $0.18 \%$, for other packaging inefficiency decreases from $-0.003 \%$ to $-1.49 \%$.

Table 6. Stochastic error distribution by type of package low price scenario

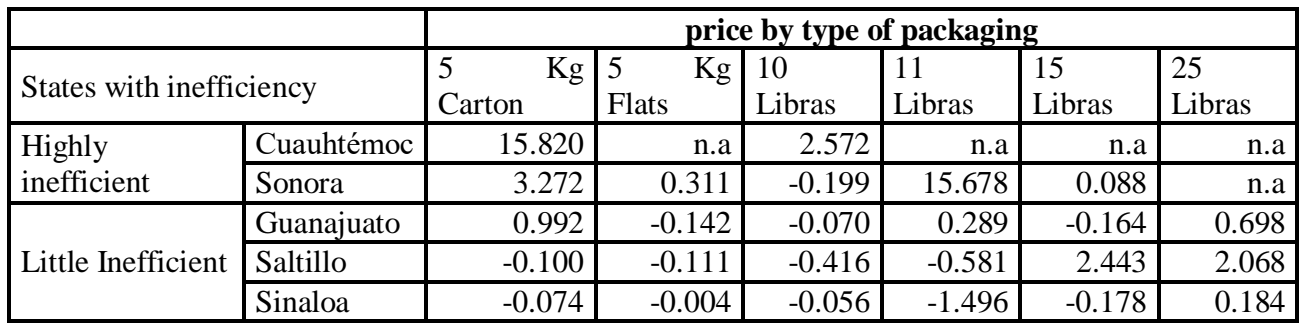

Source: author's elaboration based on information provided by producers.

In the low-price scenario, the Sonora company resulted in a stochastic error distribution reaching its maximum in the 11-pound package by increasing this inefficiency by $15 \%$, this percentage being the worst scenario in the application of the stochastic frontier.

It is worth mentioning the Saltillo company because being a company with a high technology would have to comply with the assumption of being efficient in each of its cost components, however, the result was that, even though its inefficiency is small, the model finds a degree of convergence in the interaction of cost and the random variable. 


\subsection{Random variable: exchange rate}

The distribution of the stochastic error when the uncontrolled variable was the exchange rate (Table 7), changed the situation that was presented with the market price, in this case the company of Sonora for example, in the scenario of the high price, step from being highly inefficient to little inefficient, and the Saltillo company faces the other way. This situation that is presented within the companies by the exchange rate is mainly due to the fact that they are companies that export tomatoes and the exchange rate is a variable that ultimately affects their efficiency.

As with the market price variable, the exchange rate reflects that the unit located in Cuauhtémoc continues to be the most inefficient, however it must be clarified that the exchange rate and market price coefficients are not equal, recalling that the coefficient is the one that determines the percentage in which the company is or is not inefficient, because the average of the coefficient is smaller in the exchange rate than in the market price. Even with this clarification, it is important to highlight the Cuauhtémoc case, since it presents a coefficient of increase in the inefficiency, $1.86 \%$ and $1.14 \%$ in the packages of $5 \mathrm{~kg}$ Carton and Flats, respectively, in the case of 10 and 15 pound packages the situation observed is different, since the variable contributes to the reduction of inefficiency, for the rest of the packages there is no convergence.

In the case of the Saltillo company it is observed that, although the coefficient is not as high as in Cuauhtémoc, it manages a certain level of inefficiency that ranges from $1.4 \%$ to $0.75 \%$ in all packages except the 25 pound packaging that collaborates to reduce this coefficient, this case is very important to highlight it as it is, as already mentioned above, a company with high technology that is not being efficient in the management of the components of the cost that it owns, which is incurring in levels of inefficiency, equal or superior in some cases to those of companies with medium technology.

The low price scenario (Table 8 ) in terms of the exchange rate variable shows again changes in companies that are highly inefficient and inefficient; this time it is worth mentioning the case of the Sonoran company as it returns to its highly inefficient position shown when the random variable was the market price, even surpassing the Cuauhtémoc company since it has indicators from $1.57 \%$ to $0.35 \%$, 


\section{EVALUATION OF COST EFFICIENCY IN TOMATO GREENHOUSES}

these indicators still when they are not comparable with the percentages obtained with the distribution of the stochastic error with the market price reflect inefficiency in the company and a negative influence on the cost components analyzed, since it increases their inefficiency.

Table 7. Stochastic error distribution high price scenario

\begin{tabular}{|c|c|c|c|c|c|c|c|}
\hline \multirow{2}{*}{\multicolumn{2}{|c|}{ States with inefficiency }} & \multicolumn{6}{|c|}{ Exchange Rate } \\
\hline & & $\begin{array}{l}5 \\
\text { Carton }\end{array}$ & $\begin{array}{ll}5 & \mathrm{Kg} \\
\text { Flats } & \end{array}$ & $\begin{array}{l}10 \\
\text { Libras }\end{array}$ & $\begin{array}{l}11 \\
\text { Libras }\end{array}$ & $\begin{array}{l}15 \\
\text { Libras }\end{array}$ & $\begin{array}{l}25 \\
\text { Libras }\end{array}$ \\
\hline \multirow{2}{*}{$\begin{array}{l}\text { Highly } \\
\text { inefficient }\end{array}$} & Cuauhtémoc & 1.862 & 1.141 & -0.614 & n.a. & -0.489 & n.a. \\
\hline & Saltillo & 0.875 & 1.493 & 0.760 & 1.355 & 1.464 & -0.512 \\
\hline \multirow{3}{*}{ Little Inefficient } & Guanajuato & 0.194 & 0.194 & 0.194 & 0.194 & 0.194 & 0.990 \\
\hline & Sonora & 0.009 & -0.307 & -1.751 & 0.450 & -1.751 & n.a. \\
\hline & Sinaloa & 0.742 & 0.742 & 0.742 & 0.742 & 0.742 & 0.742 \\
\hline
\end{tabular}

Source: author's elaboration based on information provided by producers.

Table 8. Distribution of stochastic error exchange rate scenario low price

\begin{tabular}{|c|c|c|c|c|c|c|c|}
\hline \multirow{2}{*}{\multicolumn{2}{|c|}{ States with inefficiency }} & \multicolumn{6}{|c|}{ Exchange Rate } \\
\hline & & \multirow{2}{*}{$\begin{array}{ll}5 & \mathrm{Kg} \\
\text { Carton } & \\
& -0.338\end{array}$} & \multirow{2}{*}{$\begin{array}{ll}5 \quad \mathrm{Kg} \\
\text { Flats } \\
\\
\\
\end{array}$} & \multirow{2}{*}{$\begin{array}{l}\begin{array}{l}10 \\
\text { Libras } \\
-0.649\end{array} \\
\end{array}$} & \multirow{2}{*}{ 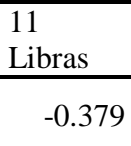 } & \multirow{2}{*}{ 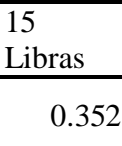 } & \multirow{2}{*}{$\begin{array}{l}25 \\
\text { Libras } \\
\\
\\
\text { n.a }\end{array}$} \\
\hline Highly & Saltillo & & & & & & \\
\hline & Sonora & 1.262 & 1.044 & 1.044 & 1.599 & 1.502 & n.a \\
\hline \multirow{3}{*}{$\begin{array}{l}\text { Little } \\
\text { Inefficient }\end{array}$} & Guanajuato & 0.753 & 0.753 & 0.753 & 0.753 & 0.753 & 1.869 \\
\hline & Cuauhtémoc & n.a & n.a & -0.623 & n.a & n.a & n.a \\
\hline & Sinaloa & 0.651 & 0.651 & 0.651 & 0.651 & 0.651 & 0.651 \\
\hline
\end{tabular}

Source: author's elaboration based on information provided by producers.

Saltillo, on the other hand, continues to show the trend of inefficiency shown in the scenarios discussed above, reflects levels of inefficiency in two of the six types of packaging analyzed. 
The Sinaloa firm continues to be efficient in managing its costs and although in the two types of scenarios the inefficiency that shows the distribution of the random variable is positive the coefficient that presents in both types of scenario continues below $1 \%$, it is say, although the impact is minimal there is no significant influence of the random variable on the cost components shown by this company.

\subsection{Random variable: natural gas price}

Within the high price scenario when the uncontrolled variable is the price of natural gas, there are no coefficients that show high or low inefficiency, with the results shown in Table 9 shows that the price of natural gas is the uncontrolled variable which represents a minor influence on the cost structure of the companies analyzed.

Table 3. Stochastic error distribution natural gas price scenario high price

\begin{tabular}{|c|c|c|c|c|c|c|c|}
\hline \multirow{2}{*}{\multicolumn{2}{|c|}{ States with inefficiency }} & \multicolumn{6}{|c|}{ Natural gas price } \\
\hline & & \multirow{2}{*}{$\begin{array}{ll}5 & \mathrm{Kg} \\
\text { Carton } \\
\\
\end{array}$} & \multirow{2}{*}{$\begin{array}{|lr|}5 & \mathrm{Kg} \\
\text { Flats } & \\
& 0.099 \\
\end{array}$} & \multirow{2}{*}{$\begin{array}{l}\begin{array}{l}10 \\
\text { Libras } \\
0.099\end{array}\end{array}$} & \multirow{2}{*}{$\begin{array}{l}\begin{array}{l}11 \\
\text { Libras } \\
0.099\end{array}\end{array}$} & \multirow{2}{*}{$\begin{array}{l}\frac{15}{\text { Libras }} \\
0.099\end{array}$} & \multirow{2}{*}{\begin{tabular}{|l|}
$\begin{array}{l}25 \\
\text { Libras }\end{array}$ \\
0.099
\end{tabular}} \\
\hline Highly & Sinaloa & & & & & & \\
\hline & Saltillo & 0.224 & 0.178 & 0.041 & 0.178 & 0.168 & n.a. \\
\hline \multirow{3}{*}{ Little Inefficient } & Guanajuato & -0.115 & -0.115 & -0.141 & -0.115 & -0.115 & -0.057 \\
\hline & Sonora & n.a. & -0.007 & -0.053 & -0.016 & n.a. & n.a. \\
\hline & Cuauhtémoc & -0.012 & 0.023 & n.a. & n.a. & -0.088 & n.a. \\
\hline
\end{tabular}

Source: author's elaboration based on information provided by producers.

However, interesting cases continue to occur with the error distribution; in the first instance it is shown that the Sinaloa company now occupies the place in highly inefficient companies, because although the coefficient of inefficiency is very small $(0.09 \%)$, it is positive and greater than the coefficients shown by the other units. Saltillo continues to show convergence with random variables.

It should be noted on this occasion that the company is located in Cuauhtémoc as it goes to the area of inefficient units, thanks to the fact that in three of the six packages analyzed there is no convergence, while in those that if convergence is 


\section{EVALUATION OF COST EFFICIENCY IN TOMATO GREENHOUSES}

found the coefficient is less than $1 \%$ both in increase of inefficiency and in a decrease of inefficiency.

Within the low-price scenario, the distribution of the error does not show significant changes in the levels of the coefficients, but does show significant changes in the distribution and classification of the producing units. First, there is the change of the Guanajuato company that, for a single occasion, appears in the high levels of inefficiency. This is due to the fact that the inefficiency that it shows, although minimal in coefficient is positive, in contrast to other companies.

Table 4. Stochastic error distribution natural gas price low price scenario.

\begin{tabular}{|l|l|r|r|r|r|r|r|}
\hline \multirow{2}{*}{ States with inefficiency } & \multicolumn{7}{|c|}{ Natural gas price } \\
\cline { 3 - 8 } & 5 Kg Carton & 5 Kg Flats & 10 Libras & 11 Libras & 15 Libras & 25 Libras \\
\hline \multirow{2}{*}{$\begin{array}{l}\text { Highly } \\
\text { inefficient }\end{array}$} & Guanajuato & 0.068 & 0.068 & 0.068 & 0.068 & 0.068 & 0.080 \\
\cline { 2 - 8 } & Sonora & -0.088 & -0.089 & -0.097 & n.a & -0.008 & n.a \\
\hline \multirow{2}{*}{$\begin{array}{l}\text { Little } \\
\text { Inefficient }\end{array}$} & Cuauhtémoc & n.a & n.a & -0.087 & n.a & n.a & n.a \\
\cline { 2 - 8 } & Sonora & -0.088 & -0.089 & -0.097 & n.a & -0.008 & n.a \\
\cline { 2 - 8 } & Sinaloa & -0.066 & -0.066 & -0.066 & -0.066 & -0.066 & -0.066 \\
\hline
\end{tabular}

Source: author's elaboration based on information provided by producers.

The Sonora unit presents levels of negative inefficiency, which means that it decreases its levels, emphasizes the behavior of the company of Cuauhtémoc as it has the best scenario as it does not find convergence in 5 of the 6 types of packaging.

\section{Cost stochastic border, the case of Monterrey and Parral}

The units of analysis of this research included two companies that showed a highly efficient behavior, these units have high technology and a structure of costs able to withstand the fluctuations of both the exchange rate, the price of natural gas and the price of market in each of the packages analyzed in the scenarios that this research is located.

At the time of the application of the model when looking for the influence of the uncontrolled variables on the composition of the costs of these companies did not obtain convergence, that is to say, the model showed that these units are not affected by the external conditions to the company and have the technology and context necessary for the optimum production of tomatoes for export. 


\section{Cost stochastic frontier, the case of Guanajuato}

Among the companies that work with medium level technology, it is worth noting the case of the Guanajuato unit, because it is a company that in each of the scenarios and with the three uncontrolled variables revealed an efficient behavior. The coefficients and signs that were presented within this unit were definitive because even though it showed that the inefficiency increased or decreased according to the conditions established for each analyzed scenario, the coefficient revealed that the influence of the exchange rate, the price of natural gas and the market price by type of packaging does not impact on the composition of the cost. The above is mainly due to the level of technology it manages, since in several scenarios analyzed this company proved to have a composition of stable cost and little affected by the external conditions.

\section{Conclusions}

With the application of the stochastic frontier model, the influence of external variables on the cost structure of the producing units analyzed, showing different scenarios, showed that, on some occasions, externalities are the cause of the possible inefficiency can present in them, but contrary to what is established in theory, there are some units that show that the inefficiency with which they count is diminished by the influence of uncontrolled variables.

Cuauhtémoc and Sonora proved to be vulnerable units to external conditions and with cost components that do not have sufficient strength to resist the impact that these variables exert on them. In contrast, the Monterrey and Parral units have a cost composition capable of absorbing the effects that the external variables have, this explains the level of technology they have and the performance they have.

Saltillo, even though it has high technology, deserves special mention because the uncontrolled variables have an impact on the cost composition, revealing that this unit is vulnerable to external conditions. Finally, the units in Guanajuato and Sinaloa have the most efficient cost structures; external conditions do not pose a danger when measuring inefficiency. This is supported by the coefficients of the 


\section{EVALUATION OF COST EFFICIENCY IN TOMATO GREENHOUSES}

stochastic error distribution, which in a few cases exceeded $1 \%$ both in increase and decrease in inefficiency, this is an indicator of the strength of these companies, especially the unit of Guanajuato which is the one that maintains a more stable behavior of the seven units analyzed in this investigation.

Sinaloa is supported by the importance of the production volume and production value generated by within the national scope, these are indicators that collaborate so that its cost structure is one of the strongest within the units analyzed; with all this the units must establish strategies that lead them to a better functioning.

\section{Recommendations}

Each type of packaging represents a different market price, which was analyzed individually for each producing unit, resulting in an efficient type of packaging for each of which the above-mentioned conclusions were derived and which resulted in the proposal of different strategies presented below.

The first strategy proposal is for each producing unit to adopt the packaging for which its cost structure is adequate, each of the units analyzed in this investigation resulted in a certain type of packaging making the operation efficient according to the structure of the costs, for which it would be convenient to use that type of packaging.

For production units to produce in a type of packaging they must know the characteristics of the market. One of these characteristics is the time it must remain in the market, during the analysis of each of the units it was concluded that the best package for all was the 25-pound one.

This type of packaging has the characteristic that it remains throughout the year in the market, it means the 52 weeks, not only by cycle as produced by the units analyzed, from which the first strategy based on cost leadership is derived.

The strategy is the organization of producers that allows to supply the 52 weeks of the year to the target market, that is, to the United States. The organization that the producers of the analyzed companies can reach and the decisions on the type of 
packaging to which they are produced can be definitive aspects in the improvement of the efficiency levels of the producing units.

The 10-pound package also represents a good option for all companies, even though it is not as efficient for all companies, their levels of inefficiency are very small in all the scenarios previously presented, which means that they adapt to the structures of costs of the companies that were analyzed and that even collaborates with the decrease of inefficiency in some of the units.

The great advantage of this type of packaging for the Mexican unit is that its presence in the market occurs during the months of February to May, November and December, months in which the producer can meet that demand.

The strategy suggested for this type of packaging is for the production units located in Guanajuato, Sonora and Saltillo, as the results from the stochastic frontier support that tomato production must be carried out in this type of packaging, since inefficiency decreases of the companies.

\section{References}

Aigner D.J., Lovell C.A.K., Schmidt P. (1977), Formulation and estimation of stochastic frontier production function models, ,Journal of Econometrics”, vol. 6 no. 1, pp. 21-37.

Asmild M., Hougaard J.L. (2006), Economic versus environmental improvement potentials of Danish pig farms, „Agricultural Economics”, vol. 35 no. 2, pp. 171-181.

Ayoola J.B. (2014), Comparative economic analysis of tomato (Lycopersicum esculenta) under irrigation and rainfed systems in selected local government areas of Kogi and Benue, Nigeria. „Journal of Development and Agricultural Economics", vol. 6 no. 11, pp. 466-471.

Bateman I.J., Brouwer R., Davies H., Day B.H., Deflandre A., Di Falco S. et al. (2006), Analysing the agricultural costs and non-market benefits of implementing the Water Framework Directive, ,Journal of Agricultural Economics", vol. 57 no. 2, pp. 221-237.

Batesse G.E., Coelli T.J. (1995), A model for technical inefficiency effects in a stochastic frontier production function for panel data, „Empirical Economics”, vol. 20, pp. 325-332.

Benach A.L. (2005), Estudio para la definición de la Estructura de Costos de Producción Agrícola de Arroz en Costa Rica, Instituto de Investigaciones en Ciencias Económicas, Universidad de Costa Rica [unpublished work].

Bojnec S., Latruffe L. (2011), Farm size and efficiency during transition. Insights from Slovenian farms, „Transformations in Business and Economics”, vol. 10 no. 3, pp. 104-116. 


\section{EVALUATION OF COST EFFICIENCY IN TOMATO GREENHOUSES}

Calvin L., Cook R. (2005), North American greenhouse tomatoes emerge as a major market force, „Economic Research Service”, April, https://www.ers.usda.gov/amber-waves/2005/april/northamerican-greenhouse-tomatoes-emerge-as-a-major-market-force/ [08.09.2018].

CIA ( 2017), The world factbook. Field listing: exports - commodities, https://www.cia.gov/library/publications/the-world-factbook/fields/2049.html [08.09.2018].

Cook R.L., Calvin L. (2005), Greenhouse tomatoes change the dynamics of the North American fresh tomato industry, Economic Research Report no. 2, United States Department of Agriculture, http://ucce.ucdavis.edu/files/datastore/234-447.pdf [08.09.2018].

Davidova S., Latruffe L. (2007), Relationships between technical efficiency and financial management for Czech Republic farms, „Journal of Agricultural Economics”, vol. 58 no. 2, pp. 269-288.

Dodson M., Bachmann J., Williams P. (2002), Organic greenhouse tomato production. appropriate technology transfer for rural areas, www.attra.ncat.org [08.09.2018].

Engindeniz S., Tuzel Y. (2006), Economic analysis of organic greenhouse lettuce production in Turkey, ,Scientia Agricola”, vol. 63 no. 3, pp. 285-290.

FAO (2018), FaoStat, http://www.fao.org/faostat/en/\#data/QC [08.09.2018].

FIRA (2016), Panorama agroalimentario tomate rojo, Dirección de Investigación Económica y Sectorial,

https://www.gob.mx/cms/uploads/attachment/file/200635/Panorama_Agroalimentario_Tomate_Rojo_2 016.pdf [08.09.2018].

Gorton M., Davidova S. (2004), Farm productivity and efficiency in the CEE applicant countries. A synthesis of results, ,Agricultural Economics”, vol. 30 no. 1, pp. 1-16.

Hung-Jen W., Ching-Chieng Ch., Po-Chi Ch. (2008), The cost effects of government subsidised credit. Evidence from farmers credit unions in Taiwan, „Journal of Agricultural Economics”, vol. 59 no. 1, pp. 132-149.

Henao M. (2001), Evaluación y caracterización morfológica del Lulo (Solanum quitoense). Tesis de ingeniero agronomo, Universidad Nacional de Colombia, Medellin [unpublished work].

Ibitoye S.J, Shaibu U.M., Omole B. (2015), Analysis of resource use efficiency in tomato (Solanum lycopersicum) production in Kogi State, Nigeria, „Asian Journal of Agricultural Extension, Economics \& Sociology", vol. 6 no. 4, pp. 220-229.

Kido-Cruz M., Kido A. (2007), Análisis comparativo de costos para el manejo y uso de suelo en la cuenca alta del río Caculta en Oaxaca, México, „Agrociencia”, vol. 41, pp. 355-352.

Kvaløy O., Tveteras R. (2008), Cost structure and vertical integration between farming and processing, „Journal of Agricultural Economics”, vol. 59 no. 2, pp. 296-311.

Laurinavičius E., Rimkuvienė D. (2017), The comparative efficiency analysis of EU members agriculture sectors, „Rural Sustainability Research”, vol. 37 no. 332, pp. 10-19. 


\section{Marisol Arvizu ARMENTA}

Meeusen W., Van Den Broeck J., (1977), Efficiency estimation from Cobb-Douglas production functions with composed error, „International Economic Review”, vol. 18 no. 2, pp. 435-444.

Mysore S., Wen-fei L.U. (2002). International competition in the greenhouse production of floriculture products - lessons for New York and India, Staff paper, Department of Agricultural, Resource and Managerial Economics, Cornell University, Ithaca NY, http://publications.dyson.cornell.edu/research/researchpdf/sp/2000/Cornell_Dyson_sp0004.pdf [08.09.2018].

Pindyck R., Rubinfeld D. (2009), Microeconomía, 7th ed., Pearson, Prentice Hall.

Rasmussen S. (2010), Scale efficiency in Danish agriculture. An input distance-function approach, „European Review of Agricultural Economics”, vol. 37 no. 3, pp. 335-367.

Reyes H.M. (1995), Investigación agrícola, costo de la semilla mejorada y tasa de interés como instrumentos para el logro de la autosuficiencia alimentaria. El caso del maíz en Guatemala, 1975-90, Instituto de Ciencia y Tecnología Agrícolas, Guatemala.

Rucoba García A. et. al (2006), Análisis de la rentabilidad de un sistema de producción de tomate bajo invernadero en la región centro sur de Chihuahua, „Revista Mexicana de Agronegocios”, vol. 10 no. 19, pp. 1-10.

Sánchez López E., Barrera Serrano M.J., Zavala J. (2004), Análisis del costo de producción del algodón 2001 en Mexicali Baja California, como un elemento de diseño de política de apoyo al subsector, „Revista Mexicana de Agronegocios”, vol. 8 no. 14, pp. 198-210.

Stevenson Rodney E., (1980), Likelihood functions for generalized stochastic frontier estimation, „Journal of Econometrics”, vol. 13 no. 1, pp. 57-66.

StataCorp (2015), Stata Statistical Software. Release 14, StataCorp LP, College Station, TX.

Torres Lima P. et al. (2004), Evaluación de la rentabilidad del desarrollo regional. El marco de la agricultura, „Región y sociedad”, vol. 16 no. 29, pp. 109-144.

USDA (2016), Tomato report. Mexico continues to expand greenhouse tomato production, GAIN Report MX6021, https://gain.fas.usda.gov/Recent\%20GAIN\%20Publications/Tomato\%20Annual_Mexico\%20City_Mex ico_6-1-2016.pdf [08.09.2018].

Vasiliev N., Astover A., Mõtte M., Noormets M., Reintam E., Roostalu H. (2008), Efficiency of Estonian grain farms in 2000-2004, „Agricultural and Food Science”, vol.17 no. 1, pp. 1-40. 